\title{
What to read?
}

\author{
Richard D. Weisel, MD, ${ }^{a}$ and Spencer McGrath, BA, MA ${ }^{\mathrm{b}}$
}

Today we are inundated by a tsunami of information, and each day our inboxes are filled with more papers than we could ever digest. What to read? This is a question we face every day. How do we select from the thousands of choices?

The American Association for Thoracic Surgery (AATS) journals have expanded, and we now have 6 journals and a robust website (AATS Online). We have an exceptional amount of material from the AATS family alone.

To meet this challenge, the AATS journals propose new initiatives to curate our content and place it in the context of the current literature to assist you (our readers) to make your choice:

\section{WHAT TO READ?}

Table 1 lists these new initiatives.

We expanded our cadre of outstanding Feature Editors, who together with the Associate Editors from our journals and invited world experts will provide you with their selection of the top 10 best papers for important topics for each of our subspecialties: Adult, Congenital, and Thoracic.

\section{Invited Expert Reviews}

The Feature and Associate Editors of Journal of Thoracic and Cardiovascular Surgery (JTCVS), JTCVS Open, JTCVS Techniques, Seminars, and Op Techs review topic proposals, including those chosen for presentation at the AATS meetings, the highest-downloaded papers from our journals, as well as important publications in high-impact journals. Then, the Feature Editors and invited experts review the papers on these topics from the AATS journals and seminal papers in other journals to create their top 10 lists. These mini reviews present these papers to you with commentaries. The curated lists will get you started to know what to read.

To facilitate your access to the best papers, each review has an illustrated bibliography with links to these papers and their accompanying commentaries (Figure 1).

\footnotetext{
From the a Division of Cardiac Surgery, Department of Surgery, Toronto General Hospital and Research Institute and University of Toronto, Toronto, Ontario, Canada; and ${ }^{\mathrm{b}}$ American Association for Thoracic Surgery, Beverly, Mass.

Disclosures: The authors reported no conflicts of interest.

The Journal policy requires editors and reviewers to disclose conflicts of interest and to decline handling or reviewing manuscripts for which they may have a conflict of interest. The editors and reviewers of this article have no conflicts of interest.

Address for reprints: Richard D. Weisel, MD, Toronto General Hospital, 101 College St, TMDT 3-704, Toronto, Ontario M5G, 1L7, Canada (E-mail: Richard.weisel@ uhn.ca).

J Thorac Cardiovasc Surg 2021;161:1-4

$0022-5223 / \$ 36.00$

Copyright (c) 2020 by The American Association for Thoracic Surgery

https://doi.org/10.1016/j.jtcvs.2020.10.060
}

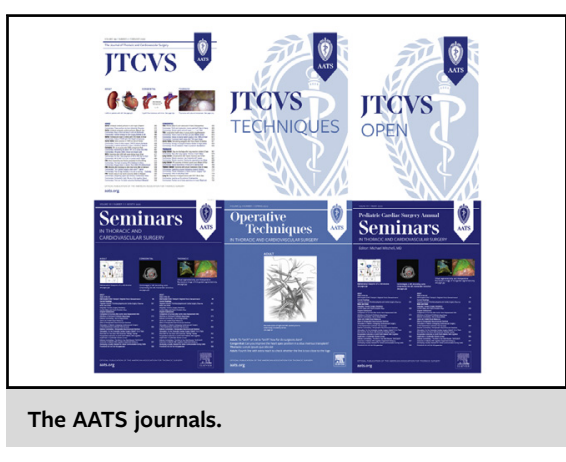

CENTRAL MESSAGE

The AATS journals propose new initiatives to curate our content and place it in the context of the current literature to assist our readers.

\section{Invited Expert Technical Reviews}

Cardiothoracic surgery is a very technically oriented specialty, and surgeons appreciate new approaches to technical challenges. In addition to the papers published in JTCVS and Seminars, we also publish brief technical reports in JTCVS Techniques and drawings in Operative Techniques. Therefore, the Feature and Associate Editors have selected important topics and reviewed all recent publications in the AATS journals as well as seminal papers in other journals to create the Invited Expert Technical Reviews. These minireviews provide the top 10 list of the best technical papers on the topics with commentaries, visuals, videos, and drawings. These lists will allow you to know which techniques to emulate.

These technical reviews also have an illustrated bibliography with links to the curated papers and their commentaries (Figure 2).

\section{Invited Expert Techniques}

The new JTCVS Techniques journal is intended to provide our community with the latest surgical approaches to challenging problems. Techniques presents an extensive number of case reports and surgical techniques. In addition, our Associate and Feature Editors have invited world experts to provide brief but detailed descriptions about their surgical approaches to important clinical conditions. These 
TABLE 1. New initiatives of AATS journals

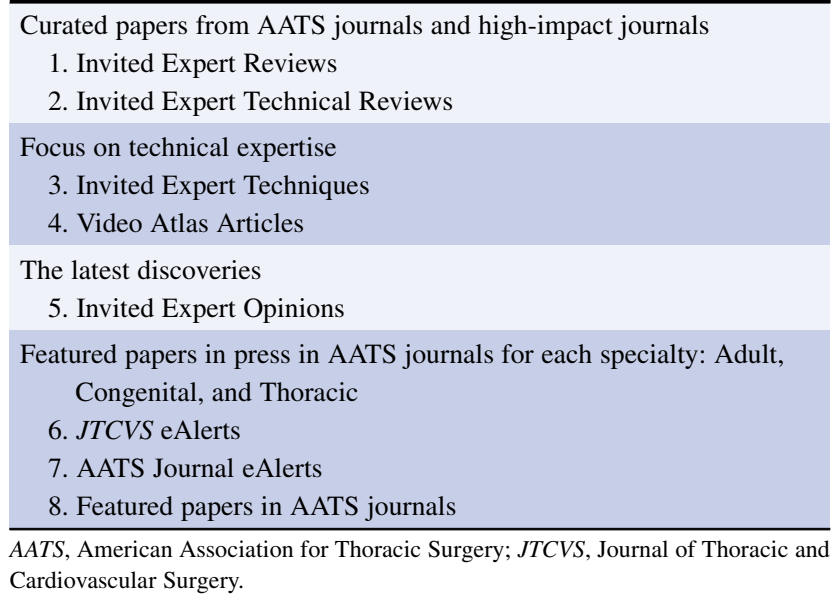

AATS, American Association for Thoracic Surgery; JTCVS, Journal of Thoracic and Cardiovascular Surgery.

invited "how I do it" papers will show you the techniques employed by masters.

\section{Video Atlas Articles}

The new JTCVS Techniques journal is also a repository of operative videos demonstrating new technical approaches in great detail. To provide the best instructional videos, the Associate and Feature Editors have invited experts to present their techniques in a series of short videos that show each of the steps required for their procedures. This atlas should provide learners and proficient surgeons with detailed directives from world experts.

\section{Invited Expert Opinions}

For the past 4 years, JTCVS has included brief editorials based on the latest advances in each of our subspecialties. These featured editorials have been very popular and our Feature Editors continue to search the literature for new developments.

\section{eAlerts}

We have developed a new method to provide our readers with the latest information from our publications specific to their specialty. The Adult, Congenital, and Thoracic AATS eAlerts provide illustrated, specialty-specific links to featured in-press content each month. We have also added AATS special specific eAlerts for feature content in the other AATS journals each month as well. You can sign up to receive these eAlerts here and you can view the gallery of previous eAlerts here.

\section{Featured Papers in AATS Journals}

Finally, to ensure that you receive the latest information, we provide an illustrated, specialty-specific links to papers in other AATS journals in each area of interest at the front of each section of the JTCVS. You can review the illustrated links for January by clicking for Adult, Congenital, and Thoracic sections.

We hope that you enjoy these new initiatives and appreciate the efforts that our editors have made to help you to decide what to read. 


\section{Aortic valve surgery in children: Recent articles from AATS Journals}

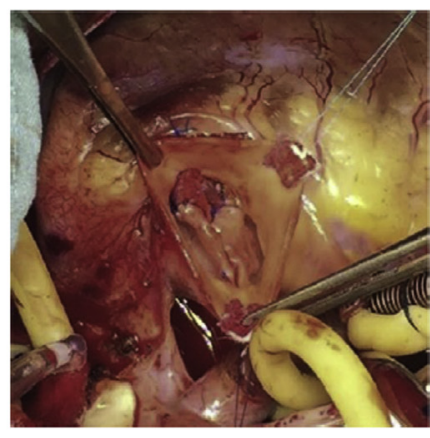

STCVS: Aortic valve interventions in pediatric patients. Bouhout I, Ba PS, El-Hamamsy I, Poirier N. Semin Thorac Cardiovasc Surg. 2019; 31(2): 277-287.

Commentary: Aortic valve interventions in children: Still only scratching the surface. Myers P0, Pretre R. Semin Thorac Cardiovasc Surg. 2019; 31(2): 277-287.

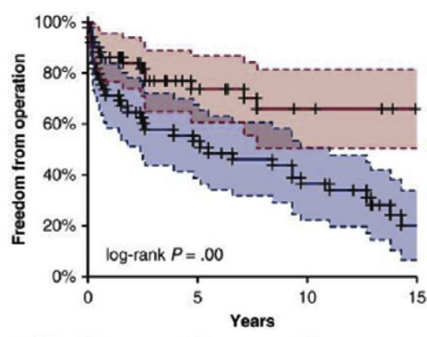

$\begin{array}{llll}+ \text { OV } & 52 & 19 & 15 \\ + \text { BV } & 51 & 23 & 15\end{array}$
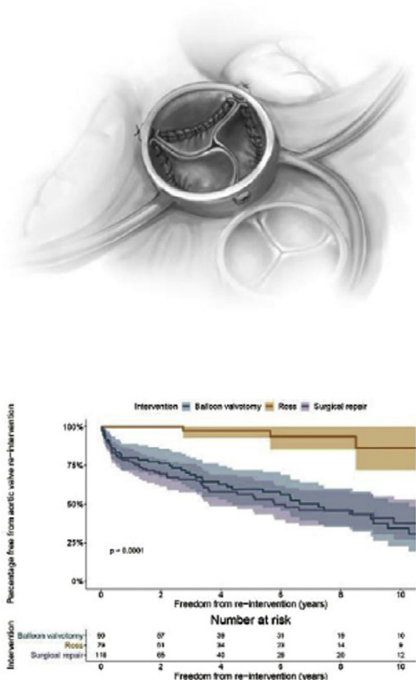

JTCVS: Aortic stenosis of the neonate: A single-center experience. Vergnat M, Asfour B, Arenz C, Suchowerskyj P, Bierbach B, Schindler E, Schneider M, Hraska V. J Thorac Cardiovasc Surg. 2019; 157(1): 318-326.e1.

Commentary: A one-way street no more? Bacha E. J Thorac Cardiovasc Surg. 2019; 157(1): 327-328.

JTCVS: Congenital aortic and truncal valve reconstruction utilizing the Ozaki technique: Short-term clinical results. Baird C, Sefton B, Chavez M, Sleeper LA, Marx GR, del Nido PJ. J Thorac Cardiovasc Surg. 2020 [In press].

Commentary: A pediatric perspective on the Ozaki procedure. Karamlou T, Pettersson G, Nigro JJ. J Thorac Cardiovasc Surg. 2020 [In press].

Commentary: Ozaki valve reconstruction in children: Is it still a valve replacement? Konstantinov IE, Naimo PS, Buratto E. J Thorac Cardiovasc Surg. 2020 [In press].

Commentary: Aortic valve reconstruction (AVRec) with neo-cuspidization: A word of caution? Bacha E. J Thorac Cardiovasc Surg. 2020 [In press].

STCVS: Strategies to minimise need for prosthetic aortic valve replacement in congenital aortic stenosis - Value of the Ross Procedure. Ivanov Y, Drury NE, Stickley J, Botha P, Khan NE, Jones TJ, Brawn W, Barron DJ. Semin Thorac Cardiovasc Surg. 2020 [In press].

Commentary: Congenital aortic valve stenosis: Defining the path to success. Burkhart HM, Thompson JL, Anderson HN. Semin Thorac Cardiovasc Surg. 2020 [In press].

FIGURE 1. Example of an illustrated bibliography of a recent Invited Expert Review. AATS, American Association for Thoracic Surgery; STCVS, Seminars in Thoracic and Cardiovascular Surgery; JTCVS, Journal of Thoracic and Cardiovascular Surgery. 


\section{Management of AAOC Artery: Recent articles from AATS Journals}
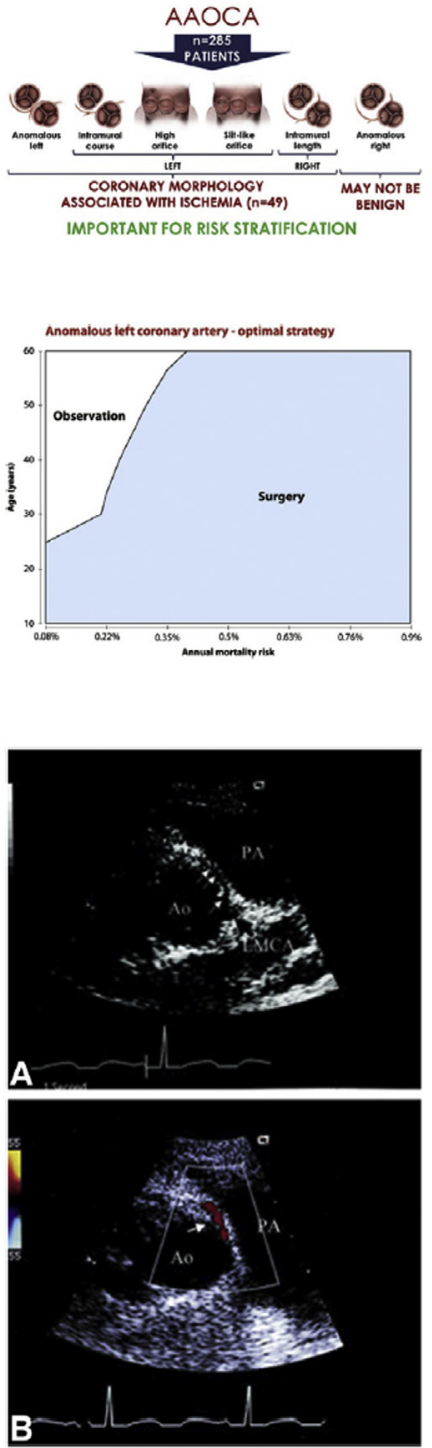

JTCVS: Features associated with myocardial ischemia in anomalous aortic origin of a coronary artery: A Congenital Heart Surgeons' Society study. Jegatheeswaran A, Devlin P, McCrindle BW, Williams WG, Blackstone, Jacobs ML, DeCampli WM, Caldarone CA, Gaynor JW, Kirklin JK, Lorber RO, Mery CM, St. Louis JD, Silvana M, Brothers JA. J Thorac Cardiovasc Surg. 2019;158(3):822-834.E3.

Commentary: The devil you know and the devil you don't. Sen DG, Kimball TR. J Thorac Cardiovasc Surg. 2019;158(3):835-836.

JTCvS: Decision analysis to define the optimal management of athletes with anomalous aortic origin of a coronary artery. Mery CM, Lopez KN, Molossi S, Sexson-Tejtel SK, Krishnamurthy R, McKenzie ED, Fraser CD Jr, Cantor SB. J Thorac Cardiovasc Surg. 2016; 152(5):1366-1375.E7.

Commentary: Tackling a complex problem via a novel approach: Decision analysis may improve quality of life for patients with anomalous aortic origin of a coronary artery. Wilder $\mathrm{T}$, Williams WG. J Thorac Cardiovasc Surg. 2016;152(5):1376-1377.

JTCVS: Expert consensus guidelines: Anomalous aortic origin of a coronary artery. Brothers JA, Frommelt MA, Jaquiss RDB, Myerburg RJ, Fraser CD Jr, Tweddell JS. J Thorac Cardiovasc Surg. 2017;135(6):1440-1457.

Commentary: Guidelines should bother us, not comfort us. DeCampli WM. J Thorac Cardiovasc Surg. 2017;153(6):1458-1461.

Commentary: Anomalous aortic origin of a coronary artery: The gaps and the guidelines. Jacobs ML. J Thorac Cardiovasc Surg. 2017;135(6):1462-1465.

FIGURE 2. Example of an illustrated bibliography of a recent Invited Expert Technical Review. AAOC, Anomalous aortic origin of a coronary artery; AATS, American Association for Thoracic Surgery; JTCVS, Journal of Thoracic and Cardiovascular Surgery. 